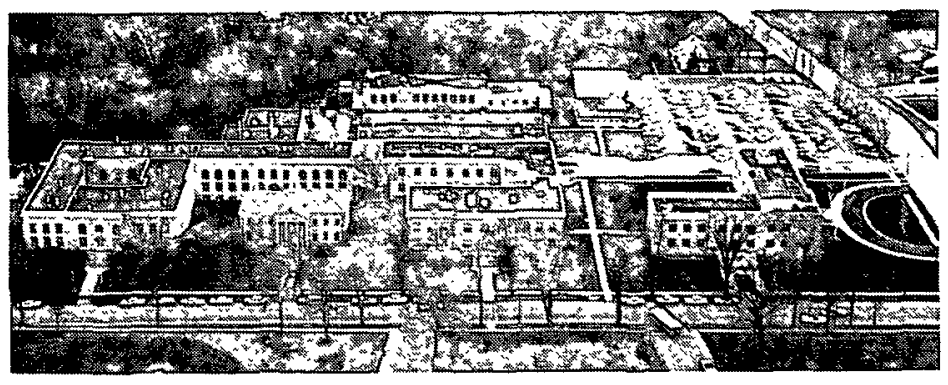

THE INSTITUTE OF PAPER CHEMISTRY, APPLETON, WISCONSIN

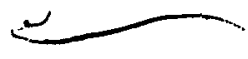

IPC TECHNICAL PAPER SERIES

NUMBER 139

ELECTRON TRANSFER REACTIONS IN PULPING SYSTEMS (I): THEORY AND APPLICABILITY TO ANTHRAQUINONE PULPING

DONALD R. DIMMEL. 
ELECTRON TRANSFER REACTIONS IN PULPING SYSTEMS (I): THEORY AND APPLICABILITY TO ANTHRAQUINONE PULPING

Donald R. Dimmel

The Institute of Paper Chemistry

Appleton, Wisconsin 54912

GENERAL SUMMARY

Institute Project 3475 has been concerned with developing a fundamental understanding of the reactions occurring during pulping and bleaching. One phase of this project research has involved a detailed investigation of the mechanism of action of anthraquinone $(\mathrm{AQ})$ as a pulping catalyst. The attached article presents a concise review of $A Q$ pulping chemistry and introduces a new view of explaining $A Q$ 's delignification reactions. The article is the first in a series of articles aimed at demonstrating the possible importance of single electron transfer reactions in pulping systems. 
ELECTRON TRANSFER REACTIONS IN PULPING SYSTEMS (I): THEORY AND APPLICABILITY TO ANTHRAQUINONE PULPING

Donald R. Dimmel

The Institute of Paper Chemistry

Appleton, Wisconsin. 54912

\begin{abstract}
A key step in the delignification of wood is the breakage of the B-aryl ether bonds of lignin. Two mechanisms are discussed for. how anthrahydroquinone (AHQ) brings about this particular fragmentation. The "adduct" mechanism involves bond formation between lignin quinonemethide ( $Q M)$ intermediates and $A H Q$, followed by fragmentation. The other mechanism ("SET" mechanism) involves a single electron transfer between $A H Q$ and a lignin QM followed by fragmentation. The literature concerning adducts and SET reactions is reviewed and analyzed. The SET mechanism must be considered as a viable alternative to one based entirely on adduct formation.
\end{abstract}

\title{
INTRODUCTION
}

Alkaline pulping processes, such as soda and kraft, we re developed long before the structures and the nature of the major components of wood were understood.1 As structural studies on cellulose, hemicellulose, and lignin progressed 2,3 so did the chemistry of pulping. Theories have evolved which now explain how hydroxide and hydrosulfide ions $\left(\mathrm{OH}^{-}\right.$and $\left.\mathrm{SH}^{-}\right)$cause carbohydrate ${ }^{2,4-6}$ and lignin 3,7 to dissolve during pulping. Most of the theories are based on experiments with model compounds rather than actual wood.

The advent of anthraquinone pulping in 1977 revitalized interest in pulping chemistry. 8 How could an organic material at a $0.1 \%$ level cause the same effect as $\mathrm{SH}^{-}$at a $6 \% 1$ leve1? Why did $\mathrm{AQ}$ processes exhibit better pulping selectivities (the amount of lignin removed vs. the amount of carbohydrates removed)? Would an understanding of $\mathrm{AQ}^{\prime}$ 's chemistry provide new insights into improving 
pulp yields, decreasing pulping reaction times, altering the structure of "residual" lignin, and developing innovative processes? Only a detalled understanding of AQ's chemistry will provide answers to these questions.

Early in the mechanistic $A Q$ studies came the realization that anthrahydroquinone ( $\mathrm{AHQ}$, a reduced form of $\mathrm{AQ}$ ) played an important role during pulping.9-11 There are several types of compounds capable of reducing $A Q$ to $A H Q$, one being carbohydrates. In a reaction with $\mathrm{AQ}$, carbohydrate end groups are oxidized and are thereby stabilized toward yield-reducing alkaline reactions.12 Certain lignin groups are also capable of converting AQ to AHQ.13,15.

Model compound studies indicate that AHQ probably promotes delignification by a combination of at least two effects: promotion of lignin fragmentation reactions $16-22$ and retardation of lignin condensation reactions. 23 During the course of these reactions, $\mathrm{AHQ}$ is oxidized to $\mathrm{AQ}$, completing one reduction-oxidation (redox) cycle. 24 Repetition of this cycle explains the catalytic activity of $\mathrm{AQ}$, high pulp ylelds, and fast delignification rates (Fig. 1).

\section{REDOX CYCLE}

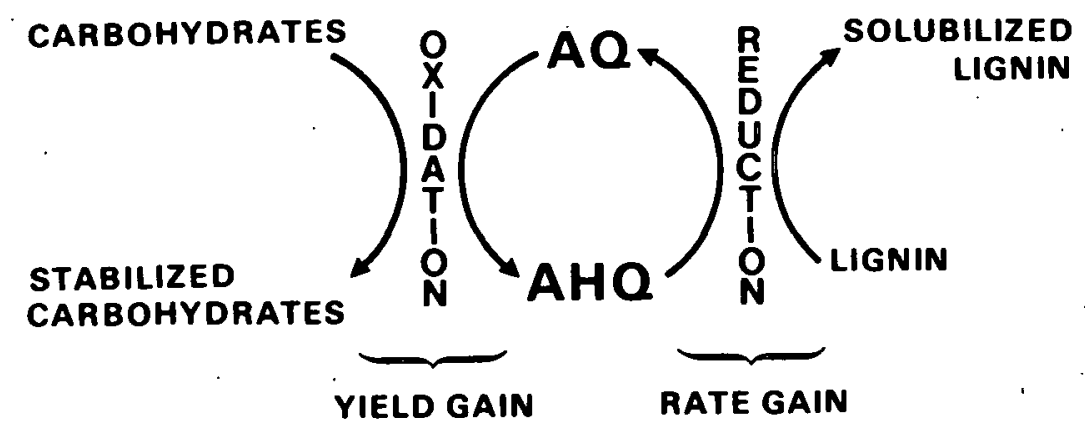

Figure 1. A redox cycle proposal for explaining the catalytic action of anthraquinone during pulping.

The next level of sophistication in the mechanistic studies was to understand the details of each of the redox reactions. In this regard, only the AHQ induced fragmentation of lignin model compounds has recelved much attention. Lignin fragmentation 
steps, which are crucial to effective alkaline pulping, are believed to involve quinonemethide (QM) intermediates.7. Two theories have evolved to explain the chemistry of an AHQ and QM interaction that gives rise to efficient fragmentation of lignin.

\section{ADDUCT MECHANISM THEORY}

At temperatures below $60^{\circ} \mathrm{C}$, AHQ couples with simple QMs to give high yields of "adducts." 24 An example is shown below. At about $60^{\circ}$, the reaction of AHQ with a simple QM (1) is reversible. 25 At $100^{\circ} \mathrm{C}$, simple adducts such as 2 disproportionate to $A Q$ and an anthrone product 3.25 This latter oxidation-reduction reaction has been interpreted as involving single electron transfer (SET) steps.
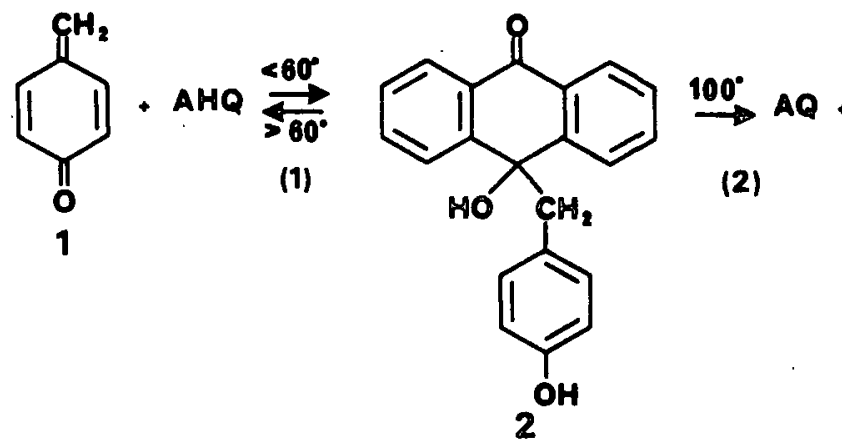<smiles>CC1(Cc2ccc(O)cc2)c2ccccc2C(=O)c2ccccc21</smiles>

Several research groups have synthesized adducts [Eq. (3)] which contain B-aryl ether groups (5) and have shown that such structures, when warmed with alkali, fragment [Eq. (4)] to liberate $A Q$ and two phenolate ions.16-19 Lignin contains large numbers of Baryl ether linkages. 3 The model studies suggest that rapid pulping rates are a result of AHQ adding to lignin QMs having neighboring $\beta$-aryl ether groups and that the resulting adducts fragment.16-18 Adducts of $\mathrm{AHQ}$ and actual lignin at $10^{\circ} \mathrm{C}$ have been reported. 26

A particularly attractive feature of the adduct theory for AHQ induced delignification is its similarity to the mechanism proposed for hydrosulfide promoted delignification of wood. Here, it is belleved that $\mathrm{SH}^{-}$adds to $\mathrm{C}_{\alpha}$ of a lignin QM [Eq. (5)] and then 

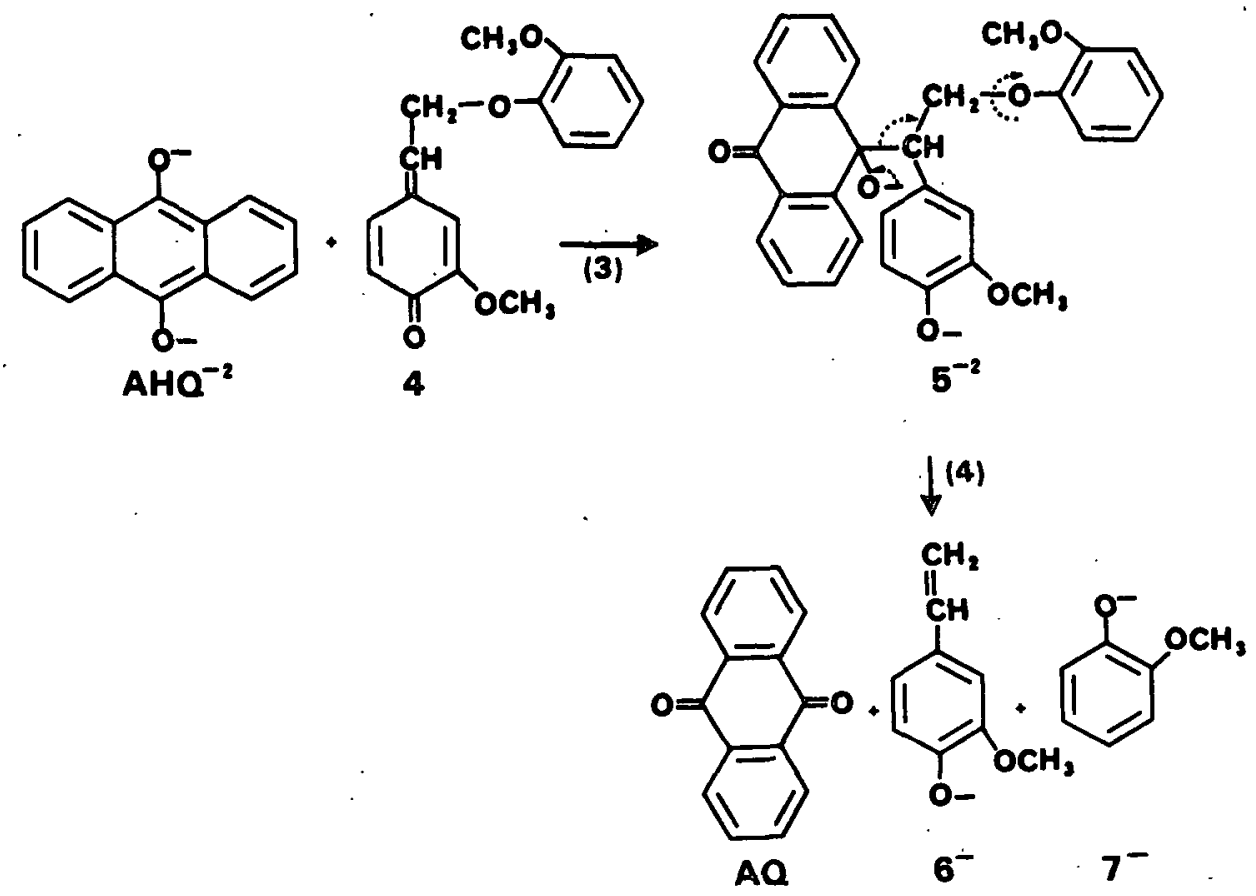

assists in a cleavage of the $C_{\beta}$-aryl ether bond by a neighboring group displacement step $[\mathrm{Eq} \cdot(6)]_{0} 7$

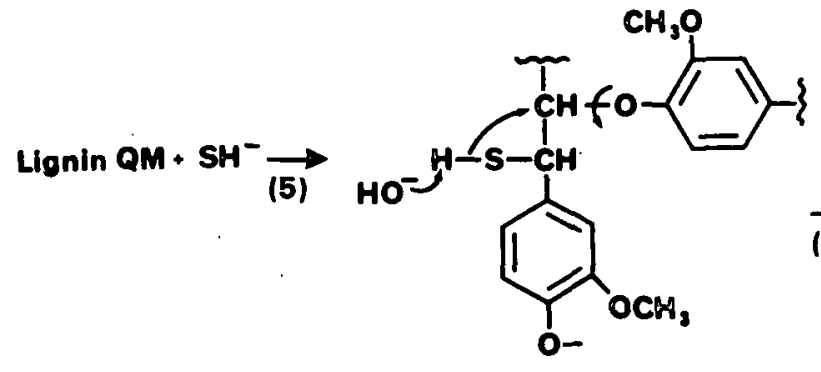

$8^{-}$<smiles>COc1ccc(-c2ccccc2)cc1OC</smiles>

$9^{-}$ $10^{-}$

\section{ELECTRON TRANSFER MECHANISM THEORY}

Could a $B$-aryl ether fragmentation reaction, such as that outlined by Eq. (3) and (4), proceed without the production of an adduct intermediate? Scheme 1 offers a mechanism of fragmentation in which $\mathrm{AHQ}^{-2}$ and $\mathrm{AHQ}^{-}$(anthrahydroquinone dianion and radical anion) act as carriers in the transfer of electrons from carbohydrates to lignin; no adducts are involved. The soluble electron transfer catalysts $\mathrm{AHQ}^{-2}$ and $\mathrm{AHQ}^{-}$are mediating a reaction between 
two insoluble polymers; analogous chemistry is known in biological systems. 27

SCHEME 1<smiles>CC(C)(O)c1ccc(O)cc1</smiles><smiles>CC(C)=Cc1ccc(O)cc1</smiles>

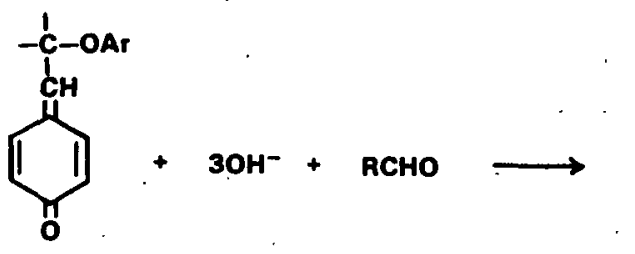<smiles>CC(C)=Cc1ccc(O)cc1</smiles>

The recent organic chemical literature is abundant in examples of reactions which were hitherto thought to be ionic nucleophilic substitutions $\left(S_{N} 1\right.$ or $S_{N} 2$ ) but have now been shown in certain cases to be single electron transfer reactions. Some of these examples will be presented here in an attempt to define the scope of SET reactions and their applicability to pulping chemistry. 
Electron spin resonance (ESR) studies have shown that some Aldol and Claisen condensation reactions proceed via SET mechanisms.27,28 For example, radical pairs of the type 13 are formed prior to production of products 14 during the aldol condensation reactions of $11 \mathrm{a}$ or $11 \mathrm{~b}$ with $12 \mathrm{c}, 12 \mathrm{~d}$ or $12 \mathrm{e} .28$ The intensity of the ESR signal, which is proportional to the level of radicals produced, was the greatest for the most hindered, slow-reacting partners.<smiles>[R]c1cc([R])c(C(=O)N[C+]2[CH]CCC2)c([R])c1</smiles>

11

12
a, $\mathbf{R}=\mathbf{H}$
a. $R^{\prime}=R^{\prime \prime}=H$
b. $R=M e$
b. $R^{\prime}=M e, R^{\prime \prime}=H$
c. $R^{\prime}=R^{\prime \prime}=M e$

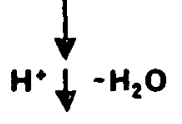<smiles>[R]c1cc([R])c(C(=CC(C)(C)C)c2ccccc2)c([R])c1</smiles>

14

Ashby and coworkers have also observed radicals in the reactions outlined in Eq. (12)-(16).30 Most of the reactions where SET mechanisms have been observed involve the production of relatively stable radicals such as trityl radicals $\left(\mathrm{Ph}_{3} \mathrm{C} \cdot\right)$ and benzophenone radical anions $\left(\mathrm{Ph}_{2} \dot{\mathrm{C}}-\mathrm{O}^{-}\right)$. Analogous, simpler systems probably would react via standard substitution mechanisms or react so rapidly by radical pathways that detection of radical intermediates would be difficult.

A characteristic of SET reactions is their insensitivity to steric bulk at the reaction site and on the nucleophile. For example, Scheme 2 outlines one of the many examples generated by Kornblum and coworkers and shows the initiation [Eq. (17)] and propagation steps [Eq. (18)-(20)] for the coupling of two hindered reactants, 15 and 16 , in a series of electron transfer reactions 


$$
\begin{aligned}
& \mathrm{Ph} \mathrm{CBr}_{3} \stackrel{\mathrm{MH}}{\rightarrow}\left[\mathrm{Ph}_{3} \mathrm{CBr}\right]^{-}[\mathrm{MH}]^{+} \rightarrow\left[\mathrm{Ph}_{3} \mathrm{C} \cdot+\mathrm{Br}^{-}+\mathrm{M}-\mathrm{H}^{+}\right] \\
& \mathrm{MH}=\mathrm{Al \textrm {H } _ { 3 }}, \mathrm{MgH}_{2}, \mathrm{HMgCl}, \mathrm{HMgBr} \\
& B_{2} \mathrm{H}_{6}, \mathrm{LiAlH}_{4}, \mathrm{NaAlH}_{4} \\
& \mathrm{Ph}_{2} \mathrm{C}=\mathrm{O}+\mathrm{Me}_{2} \mathrm{CHOLi} \rightarrow\left[\mathrm{Ph}_{2} \mathrm{C}=\mathrm{O}\right]^{-}\left[\mathrm{Me}_{2} \mathrm{CHOLI}\right]^{\dot{ }} \rightarrow \mathrm{Ph}_{2} \mathrm{CHOLi}+\mathrm{Me}_{2} \mathrm{C}=\mathrm{O} \\
& \mathrm{Ph}_{2} \mathrm{C}=\mathrm{O}+\mathrm{R}_{2} \mathrm{NLi} \rightarrow\left[\mathrm{Ph}_{2} \mathrm{C}=0\right]^{-}\left[\mathrm{R}_{2} \mathrm{NLi}\right]^{\dot{ }} \rightarrow \stackrel{\mathrm{QLi}}{\rightarrow} \stackrel{\mathrm{Ph}_{2} \mathrm{C}-\mathrm{NR}_{2}}{ } \\
& \mathrm{Ph}_{2} \mathrm{C}=\mathrm{O}+\mathrm{BuSLi} \rightarrow\left[\begin{array}{c}
\mathrm{Ph}_{2} \dot{\mathrm{C}}-\mathrm{O}_{\mathrm{\prime}}^{-} \\
\mathrm{BuS}-\mathrm{Li}
\end{array}\right] \rightarrow \mathrm{Ph}_{2} \dot{\mathrm{C}}-\mathrm{OLi}+\mathrm{BuS} \\
& \mathrm{PhCHO}+\mathrm{NaOH} \rightarrow\left[\mathrm{PhCHO}^{-} \rightarrow \mathrm{PhCO}_{2}^{-}+\mathrm{PhCH}_{2} \mathrm{OH}\right.
\end{aligned}
$$

which lead to product 18.31 Russell and coworkers have shown that similar mechanisms operate for many substitution reactions of hindered aliphatic nitro compounds. 32

In summary, SET reactions appear to be the favored mechanism for the reactions of highly hindered substances which can also form relatively stable radical intermediates. The generality of SET mechanisms in nonhindered systems is less clear, although examples are known.30e, 33-35 The examples cited here also point out that SET reactions can proceed without radical initiators. A quinonemethide, which is nonaromatic, would appear to be a good substrate for electron transfer reactions, since acceptance of an electron gives an extensively resonance stabilized, aromatic $\mathrm{QM}^{\circ}$ species. Anthrahydroquinone radical anion, $\mathrm{AHQ}^{-}$, should also be an excellent partner in electron transfer reactions, since not only is $\mathrm{AHQ}^{-}$extensively resonance stabilized but its oxidized and reduced forms, $\mathrm{AQ}$ and $\mathrm{AHQ}^{-2}$, also have good stability. In the accompanying article, 36 we demonstrate that (a) SET reactions between $\mathrm{QMs}$ and $\mathrm{AHQ}^{-}$occur and (b) appropriately substituted $\beta$-aryl ether $\mathrm{QM}^{-}$compounds fragment, as indicated in Eq. (8).

Besides the plausibilty of the reactions outlined in Scheme 1 , the arguments for SET mechanism operating during pulping are 
SCHEME 2
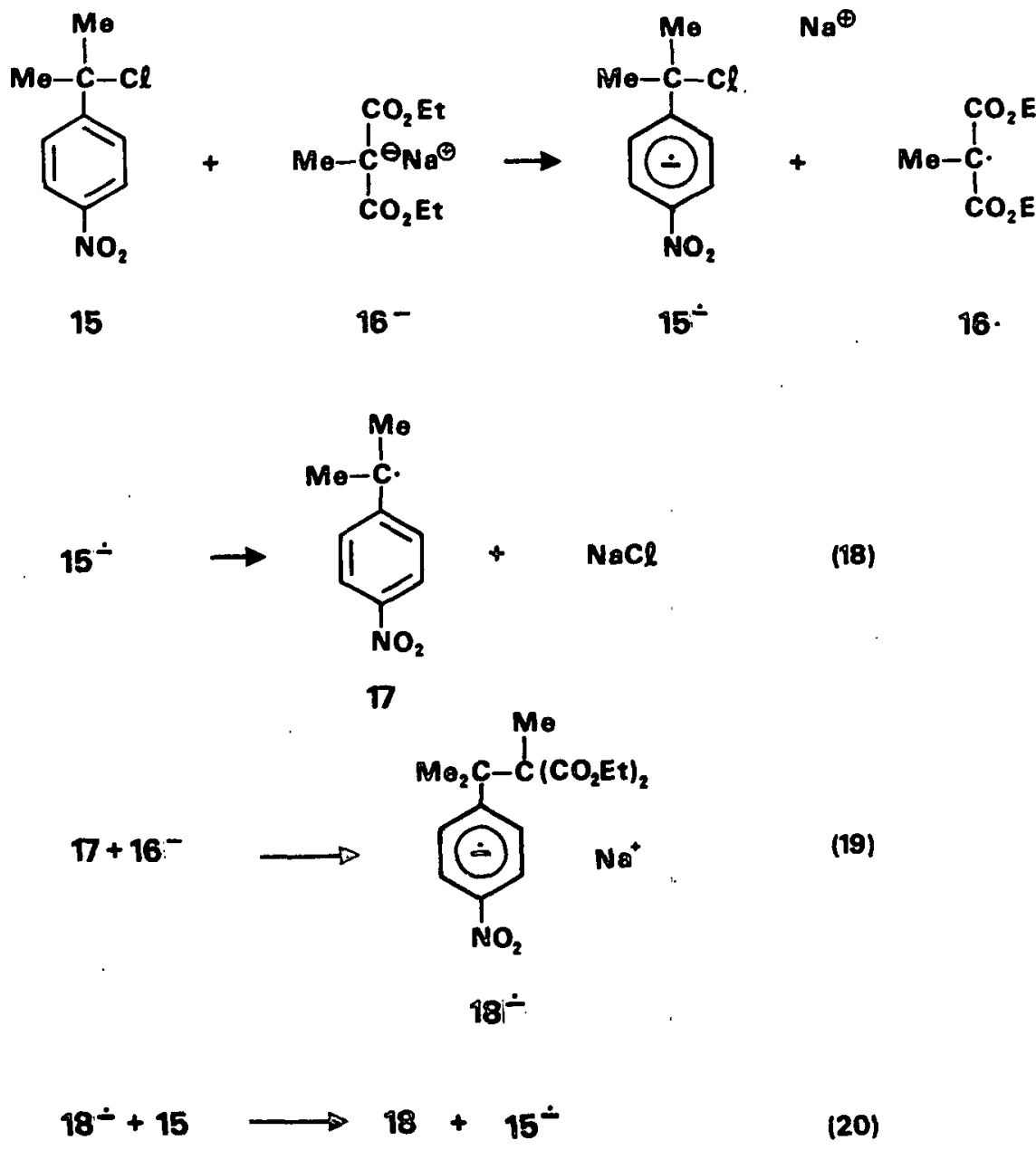

(20)

extensive. Radicals in general ${ }^{37}$ and $\mathrm{AHQ}^{\circ}$ in particular $38-40$ have been observed during pulping. We have observed two cases where $\mathrm{AHQ}^{-2}$ appears to participate in SET reactions.' One example is the reduction of adducts by $\mathrm{AHQ}^{-2}$ at $100^{\circ} \mathrm{C}$ in aqueous alkal1.25 The other is the promotion of benzaldehyde Cannizzaro reactions by $\mathrm{AQ}$ and AMS (anthraquinone monosulfonate).41 The benzaldehyde Cannizzaro reaction [Eq. (16)] has been shown to involve radical intermediates. $30 \mathrm{e}$

The reduction potentials for the two steps $\mathrm{AQ} \longrightarrow \mathrm{AHQ}^{-} \longrightarrow$ $\mathrm{AHQ}^{-2}$ are identical in water;17 thus one molecule of $\mathrm{AQ}$ ( $1 \mathrm{n}$ its $\mathrm{AHQ}^{-2}$ form) should be capable of initiating two $\mathrm{QM} \longrightarrow \mathrm{QM}^{\circ}$ conver- 
sions. This could explain the "square-root dose relationship" found for $A Q$ pulping;42 an adduct mechanism cannot. A "lineardose relationship" is observed 43 for $\mathrm{SH}^{-}$, and nucleophilic substitution mechanisms have been suggested [Eq. (5) and (6)].

A consideration of the stereochemistry of the interaction of $\mathrm{AHQ}^{-2}$. with lignin QMs argues for SET mechanisms. High yields of adducts can be achieved by reacting simple QMs (i.e., 1) with $\mathrm{AHQ}^{-2}$ in water, 24 moderately hindered $\mathrm{QMs}$ (i.e., 4) with $\mathrm{AHQ}^{-2}$ in a two-phase water-organic system, 17 and hindered QMs (i.e., 19) with AHQ in pure organic solvent systems. 44 However, the more hindered QM 20 gave only a poor yield of adduct when reacted with AHQ in organic solvents. 44 water and alkali seriously impair the yields of adducts between $\mathrm{AHQ}^{-2}$ and $\alpha$-substituted $\mathrm{QMs}$, such as $\alpha$ methyl, $\alpha$-ethyl, or $\alpha$-aryloxymethyl.24,45

We have been unsuccessful in preparing an AHQ adduct of QM 19 in the presence of water. Two methods were tried: (a) conversion of the $\alpha$-hydroxy lignin model 21 to $\alpha$-chloroacetate 22 and then treating the latter with $\mathrm{AHQ}^{-2}$ in aqueous alkall and (b) treatment of 21 with $\mathrm{BrSiMe}_{3}$ and $\mathrm{NaHCO}_{3}$ to get a stable solution of QM 19 in $\mathrm{CHCl}_{3}$ and then mixing the latter solution with aqueous $\mathrm{AHQ}^{-2}$. Significant amounts of $\alpha$-hydroxy compound 21 were recovered in each case. Apparently, the reaction of hindered QM 19 with solvent or alkali occurs in preference to adduct formation.<smiles>[R]C(C=C1C=CC(=O)C(OC)=C1)Oc1ccccc1OC</smiles>
4, $R=H$
19, $\mathrm{R}=\mathrm{CH}_{3}$
20. $\mathrm{R}=\mathrm{CH}_{2} \mathrm{OH}$<smiles>COc1cc(C(O)C(C)Oc2ccccc2OC)ccc1O</smiles><smiles>COc1cc(C(Cl)C(C)Oc2ccccc2OC)ccc1OC(C)=O</smiles> 
Quinonemethides 19 and 20 probably represent the absolute lower limit for the least crowded $\mathrm{M}$ found in lignin. Yet, In aqueous alkali (the medium used in pulping), adducts could not be made with $Q M$ 19. A specific geometry is needed to bind $\mathrm{AHQ}^{-2}$ to a lignin $Q M$ [Eq. (21)]. The resulting adduct of the polymeric material should be highly crowded around the $C_{\alpha}$ and $C_{\beta}$ positions; one of the substitutions on $C_{\alpha}$ is a quaternary substituted $\mathrm{C}_{9}$ carbon. In contrast, the distance between reactants and the stereochemical constraints should be much looser in the case of a SET mechanism. For hindered QMs, such as those of lignin, a SET mechanism may be preferred over an adduct mechanism.

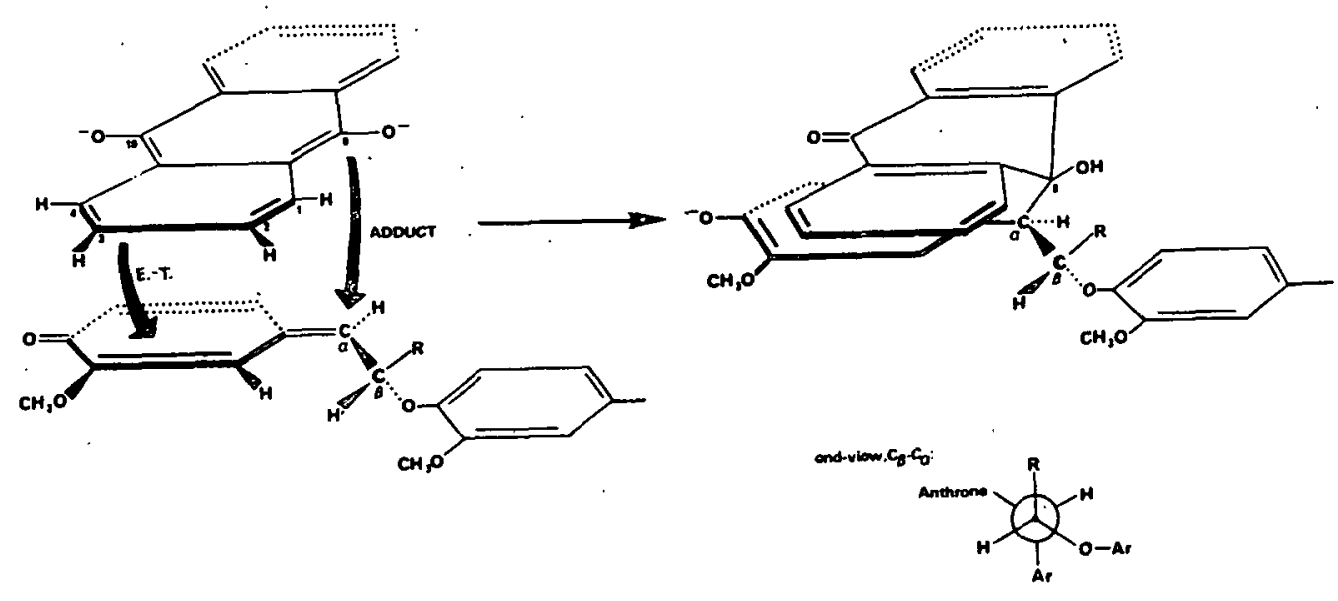

Some fairly hindered pulping catalysts, such as the rosindones, are as efficient as $\mathrm{AQ}$ at low concentrations.46 This observation is contrary to what one would expect with an adduct mechanism. Wright and Fullerton have recently demonstrated that metal complexes of porphyrin structures are efficent pulping catalysts. 47 It is easy to visualize a SET mechanism for this catalyst; an adduct mechanism appears unlikely.

Popplus and Brunow claim that anthrone causes $\beta$-aryl ether cleavage of lignin model 21 by a pathway not involving an adduct intermediate. 48 A logical explanation of their results is that anthranol anions transfer electrons to 19 intermediates to give 
fragmentation of the $Q M$ and anthranol radicals. Coupling of the radicals, followed by enolization, then gives dianthranol, an observed by-product.

Previous studies have not established that lignin QM-AHQ adducts are on the reaction pathways of fragmentation. For example, the conversion of adduct 5 to $A Q$ and phenols 6 and 7 has been interpreted in terms of a set of electron shifts as shown in Eq. (4);17 analogous fragmentation reactions are known. 49 However, since adduct formation reactions are reversible, 25 warming an adduct in alkali will give $\mathrm{AHQ}^{-2}$ and a $\mathrm{QM}$ [i.e., the reverse of Eq. (3)] which may then react by a SET mechanism to give the observed products.

The recent report 26 that adducts of $\mathrm{AHQ}^{-2}$ and actual lignin are produced at $10^{\circ}$ and can be observed by $13 \mathrm{C}$-NMR also does not establish that the adducts are reactive intermediate in the fragmentation process; they could be deadend by-products. The $1{ }^{3} \mathrm{C}$-NMR spectra do not provide much information about the nature of the "lignin adducts." Corresponding $1_{H-N M R}$ spectra26 surprisingly did not show one of the characteristics of adducts, namely an aromatic methoxyl signal at about $3.4 \delta .44,50$ Also, the molecular sizes of the "lignin adducts" were not well defined,26 especially in lieu of unusual absorption effects which can occur with gel filtration techniques. 51

\section{CONCLUSIONS}

The lifetimes of the intermediates in both the proposed adduct mechanism and SET mechanism should be extremely short at the high temperatures used in AQ pulping systems. How do we differentiate a momentary bonding - fragmentation mechanism from an electron transfer mechanism? We are attempting to tackle this difficult problem. We feel that the mechanisms by which. AHQ accelerates pulping rates are not settled. Electron transfer mechanisms offer an attractive alternative to the generally accepted adduct mechanisms.

What difference does it make if the mechanism of AHQ delignification is adduct or electron transfer? A definitive distinction 
may lead to improvements in present pulping systems and the deve1opment of new systems. We will know (a) whether to promote adduct reactions (or SET reactions) or discourage them and (b) whether to develop new pulping catalysts which will be good nucleophiles or good SET reagents.

\section{EXPERIMENTAL}

Two methods were attempted for the preparation of the adduct of $\mathrm{AHQ}^{-2}$ and $\mathrm{QM} \mathrm{19}$; both methods failed. Each method used the dithionite procedure 24 for the preparation of $\mathrm{AHQ}^{-2}$.

Method 1. A stable solution of $\mathrm{QM} 19$ in $\mathrm{CHCl}_{3}$ was prepared by the method of Ralph and Young. 52 Confirmation of the presence of QM 19 was provided by recording the NMR spectrum of 19 in $\mathrm{CDCl}_{3} .52$ The $\mathrm{CHCl}_{3} / 19$ solution was added to a cold aqueous alkaline solution of $\mathrm{AHQ}^{-2}$ and stirred at $0^{\circ} \mathrm{C}$ for 1 hour. The reaction mixture was then acidified ( $3 \mathrm{M} \mathrm{HCl}$ ) and the $\mathrm{CHCl}_{3}$ layer separated. The $\mathrm{CHCl}_{3}$ solution was combined with additional $\mathrm{CHCl}_{3}$ extracts, dried $\left(\mathrm{Na}_{2} \mathrm{SO}_{4}\right)$, and evaporated. The residue was dissolvd in $\mathrm{CDCl}_{3}$ and an NMR recorded. The signals expected for an adduct 44,50 were absent, only $A Q$ and compound 21 were detected.

Method 2. The chloroacetate $22^{53}$ dissolved in a sma11 amount of dioxane was added to an ice-cold aqueous solution of $\mathrm{AHQ}^{-2}$ and alkali. After stirring at room temperature for 30 minutes, the solution was acidified with $\mathrm{HCl}$ and the precipitate collected by filtration. A NMR of the solid dissolved in $\mathrm{CDCl}_{3}$ showed none of the expected adduct signals, 44,50 just $A Q$ and compound 21 . Analysis by GC/MS confirmed these results.

\section{REFERENCES}

1. D. W. Clayton, in The Pulping of Wood, 2nd Ed., Vol. I, Chap. 8, R. G. MacDonald (Ed.), McGraw-Hi11, New York, 1969.

2. G. D. McGinnis and F. Shafizadek, in Pulp and Paper Chemistry and Chemical Technology, 3rd Ed., Vol. I, Chap.1, J. P. Casey (Ed.), WIley and Sons, New York, 1980.

3. W. G. Glasser, ibid, Chap. 2 .

4. J. M. MacLeod and L. R. Schroeder, J. Wood Chem. Technol., 2, 187 (1982) and references cited within. 
5. E. Sjostrom, Tappi, 60(9), 151 (1977).

6. 0. Samuelson, Intern. Sympos. on Wood and Pulping Chem., Stockholm, June 9-12, 1981, Vol. II, p. 78 of the proceedings.

7. J. Gierer, Holz forschung, 36,43 (1982).

8. H. H. Holton, Pulp Paper Can., 78, T218 (1977).

9. B. I. Fleming, G. J. Kubes, J. M. MacLeod, and H. I. Bolker, Tappi, 61(6), 43 (1978).

10. K. Iiyama, A. G. Kulkarni, Y. Nomura, and J. Nakano, J. Japan Wood Res. Soc., 24, 766 (1978).

11. G. L. Simard, J. M. Genco, and K. E.'Henriksson, Jr., Tappi, $62(5), 91,19.79$.

12. 0. Samuelson, Pulp Paper Can., 81(8), 68 (1980).

13. J. S. Gratzl, EUCEPA Symposium, June 2-5, 1980, Helsinki, Finland, Paper No. 12.

14. H. Araki, D. H. Hawes, M. C. Schroeter, C. L. Chen, and J: S. Gratzl, Canadian Wood Chem. Symposium, Sept. 19-21, 1979, Harrison Hot Springs, B. C., p. 71 of Extended Abstracts.

15. P. B. Apfeld and D. R. Dimmel, J. Wood Chem. Technol., 2, 269 (1982).

16. J. R. Obst., L. L. Landucc1, and N. Sanyer, Tappi, 62(1), 55 (1979).

17. L. L. Landucci, Tappi 63(7), 95 (1980).

18. J. Gierer, O. Lindeberg, and I. Noren, Holzforschung, 33, 213 (1979).

19. H. Aminoff, G. Brunow, G. E. Miksche, and K. Poppius, Paperi Puu, 61, 441 (1979).

20. T. Yaguchi, S. Hosoya, J. Nakano, A. Satoh, Y. Nomura, and M. Nakamura, J. Japan Wood Res. Soc., 25, 239 (1979) and Japan Tappi, 33(10), 666 (1979).

21. G. Brunow and K. Poppius, Paperi Puu, 63, 783 (1981).

22. G. Brunow and K. Poppius, Acta Chem. Scand., B36, 377 (1982)。

23. D. R. Dimmel, D. Shepard, and T. A. Brown, J. Wood Chem. Te chnol., 1, 123 (1981).

24. D. R. Dimmel and D. Shepard, J. Org. Chem., 47, 22 (1982).

25. D. R. Dimmel and D.' Shepard, J. Wood Chem. Technol., 2, 73 (1982).

26. L. L. Landucci, J. Wood Chem. Technol., 1, 61 (1981). 
27. N. Tsubokawa, E. Takeshi, and M. Okawara, J. Polymer Science, 20, 2205 (1982).

28. E. C. Ashby, J. N. Argyropoulos, G. R. Meyer, and A.B. Goel, J. Amer. Chem. Soc., 105, 6788 (1982).

29. E. C. Ashby and W. S. Park, Tetrahedrom Letters, 24, 1662 (1983).

30. Ashby, et a1., Tetrahedron Letters (a) 22, 3729; (b) 22, 4209; (c) 22,4355 (1981); (d) 23,2273 (1982); (e) $2 \overline{4}, 851$ (1983).

31. N. Kornblum, Angew Chem. Int. Ed., 14, 734 (1975).

32. G. A. Russell, Chem. Stosow, 26, 317 (1982).

33. E. C. Ashby, A. B. Goel, and R. N. DePriest, J. Org. Chem., 46, 2429 (1981).

34. G. Bartoli, M. Bosco, R. D. Pozzo, and F. Ciminale, J. Org. Chem., 47, 5227 (1982).

35. C. G. Screttas, M. Micha-Screttas, and C. T. Cazianis, Tetrahedron Letters, 24, 3287 (1983).

36. D. R. Dimmel, L. F. Perry, H. L. Chum, and P. D. Palasz, J. Wood Chem. Technol., 4, next article, 1983.

37. T. N. Kleinert, Tappi, 49(3), 126 (1966).

38. M. B. Hocking, H. I. Bolker, and B. I. Fleming, Can。 J. Chem., 58, 1983 (1980).

39. S. M. Mattar and B. I. Fleming, Tappi, 64(4), 136 (1981).

40. J. E. Doyle and F. 0. Looney, Appita, 36, 219 (1982).

41. D. R. Dimmel, unpublished results.

42. D. P. Werthemann, J. Wood Chem. Technol., 1, 169 (1981).

43. D. P. Werthemann, Tappi, 65(7), 98 (1982).

44. L. L. Landucci and J. Ralph, J. Org. Chem., 47, 3486 (1982).

45. D. R. Dimmel and D. Shepard, Unpublished results.

46. D. P. Werthemann, H. Huber-Emden, P. M. Bersier, and J. Kelemen, J. Wood Chem. Techno1., 1, 185 (1981).

47. L. J. Wright and T. J. Fullerton, J. Wood Chem. Technol., in press.

48. K. Popplus and G. Brunow, 1983 International Symposium on Wood and Pulping Chemlstry, Tsukuba, Japan, Vol. 4, p. 113 of the abstracts.

49. J. March, Advanced Organic Chemistry, 2nd Ed., McGraw-H111, New York, 1977, pp. 945-9. 
50. D. R. Dimme1, J. Org. Chem., 47, 29 (1982).

51. S. Sarkanen, D. C. Teller, J. Hall, and J. L. McCarthy, Macromols., 14, 426 (1981).

52. J. Ralph and R. A. Young, J. Wood Chem. Technol., 3, 161 (1983).

53. D. R. Dimmel and D. Shepard, J. Wood Chem. Techno1., 2, 297 (1982). 